Darius Daunys $\cdot$ Petras Zemlys $\cdot$ Sergej Olenin

Anastasija Zaiko $\cdot$ Christian Ferrarin

\title{
Impact of the zebra mussel Dreissena polymorpha invasion on the budget of suspended material in a shallow lagoon ecosystem
}

Received: 6 June 2005/ Accepted: 5 December 2005/Published online: 4 February 2006

(C) Springer-Verlag and AWI 2006

\begin{abstract}
The role of the zebra mussel Dreissena polymorpha in redistribution of total particulate material (TPM) between the water column and bottom sediment was estimated using the TPM budget for a mussel bed in the Curonian lagoon, the Baltic Sea. Seasonal clearance rates were derived from the TPM budget assuming two resuspension scenarios: no resuspension and full resuspension of biodeposits. Estimated clearance rates for both scenarios were compared with the rates calculated from the population clearance rate model. Seasonal clearance rates estimated using the population model (1.1 and $11.81 \mathrm{~g}^{-1}$ SFDW $\mathrm{day}^{-1}$ ) fitted well into the interval of seasonal clearance rates calculated from TPM budgets assuming no resuspension of biodeposits (3.2 and $21.41 \mathrm{~g} \mathrm{SFDW}^{-1} \mathrm{day}^{-1}$ ). In the scenario with biodeposits resuspension clearance rates were much higher (57.4 and $148.9 \mathrm{~g} \mathrm{SFDW}^{-1} \mathrm{day}^{-1}$ ). The ratio of clearance to residence time was highly dependent on the fate of biodeposits. Therefore its use in interpretation of the species impact on TPM was limited. An alternative measure based on the ratio of the amount of TPM biodeposited to TPM transported into the bed was used. It was found that zebra mussels are able to deposit between 10 and $30 \%$ of the incoming TPM, and the amount of biodeposited material was correlated with water residence time. Results indicate that the impact of zebra mussels on TPM in the lagoon is small relative to the high transport rates of TPM over the bed. However, annual biosedimentation rate $\left(\sim 590 \mathrm{~g} \mathrm{~m}^{-2}\right)$ in the mussel bed was higher than physical deposition rate
\end{abstract}

Communicated by K. Reise

D. Daunys $(\bowtie) \cdot$ P. Zemlys $\cdot$ S. Olenin $\cdot$ A. Zaiko

Coastal Research and Planning Institute,

Klaipeda University, H. Manto 84,

92294 Klaipeda, Lithuania

E-mail: darius@corpi.ku.lt

Tel.: + 370-46-398847

Fax: + 370-46-398845

C. Ferrarin

ISMAR-CNR, S. Polo 1364, Venice, Italy $\left(\sim 380 \mathrm{~g} \mathrm{~m}^{-2}\right)$ in accumulation areas devoid of large suspension feeders. We suggest that a local impact due to enhanced availability of organic material to other trophic groups of associated benthic organisms may be more significant than effects on TPM pathways at an ecosystem scale.

Keywords Invasive species - Total particulate material budget $\cdot$ Clearance rate $\cdot$ Biodeposition

\section{Introduction}

Spread of the zebra mussel Dreissena polymorpha into the inland and coastal waters of the Baltic Sea basin has largely taken place in the past 200 years. In the Curonian lagoon, a shallow coastal water body in the southeastern part of the Baltic Sea, the zebra mussel appeared in the early 1800s (Olenin et al. 1999 and references therein). Being able to form dense clumps and to dominate in terms of benthic community biomass, D. polymorpha became an important component of the lagoon's ecosystem (Olenin and Leppäkoski 1999). Zebra mussels cause multiple functional changes in invaded ecosystems (e.g. Karatayev et al. 2002), and similar effects could be expected for the Curonian lagoon. However, direct preand post-invasion comparisons are not possible since the zebra mussel invasion in the lagoon happened long before ecological research commenced.

In this study we consider one of the functional aspects of D. polymorpha invasion: its role in redistribution of suspended particles between the water column and bottom sediment. We estimated the species' impact on total particulate material (TPM) fluxes in different seasons using a TPM budget for the zebra mussel bed. Seasonal clearance rates were also calculated using a population clearance rate model. These rates were compared with those derived from the TPM budget. The species role is evaluated in the context of the suspended material budget of the lagoon and its hydrological regime. 
Study area

The Curonian lagoon is a large $\left(1,584 \mathrm{~km}^{2}\right)$, shallow (mean depth $3.8 \mathrm{~m}$ ) and mainly freshwater body connected to the south-eastern part of the Baltic Sea by a narrow strait (Fig. 1). The Nemunas River brings 98\% of the total freshwater runoff and enters the lagoon in its central area, dividing the water body into two different parts (Jurevicius 1959). The northern part is a transitory riverine-like system transporting freshwater into the sea and receiving seawater during wind driven short-term inflow events. The lacustrine southern part is characterised by a relatively closed water circulation and lower current velocities. Therefore it serves as a main depositional area of the lagoon.

The annual Nemunas River discharge $\left(\sim 23 \mathrm{~km}^{3}\right)$ exceeds the lagoon's water volume approximately four

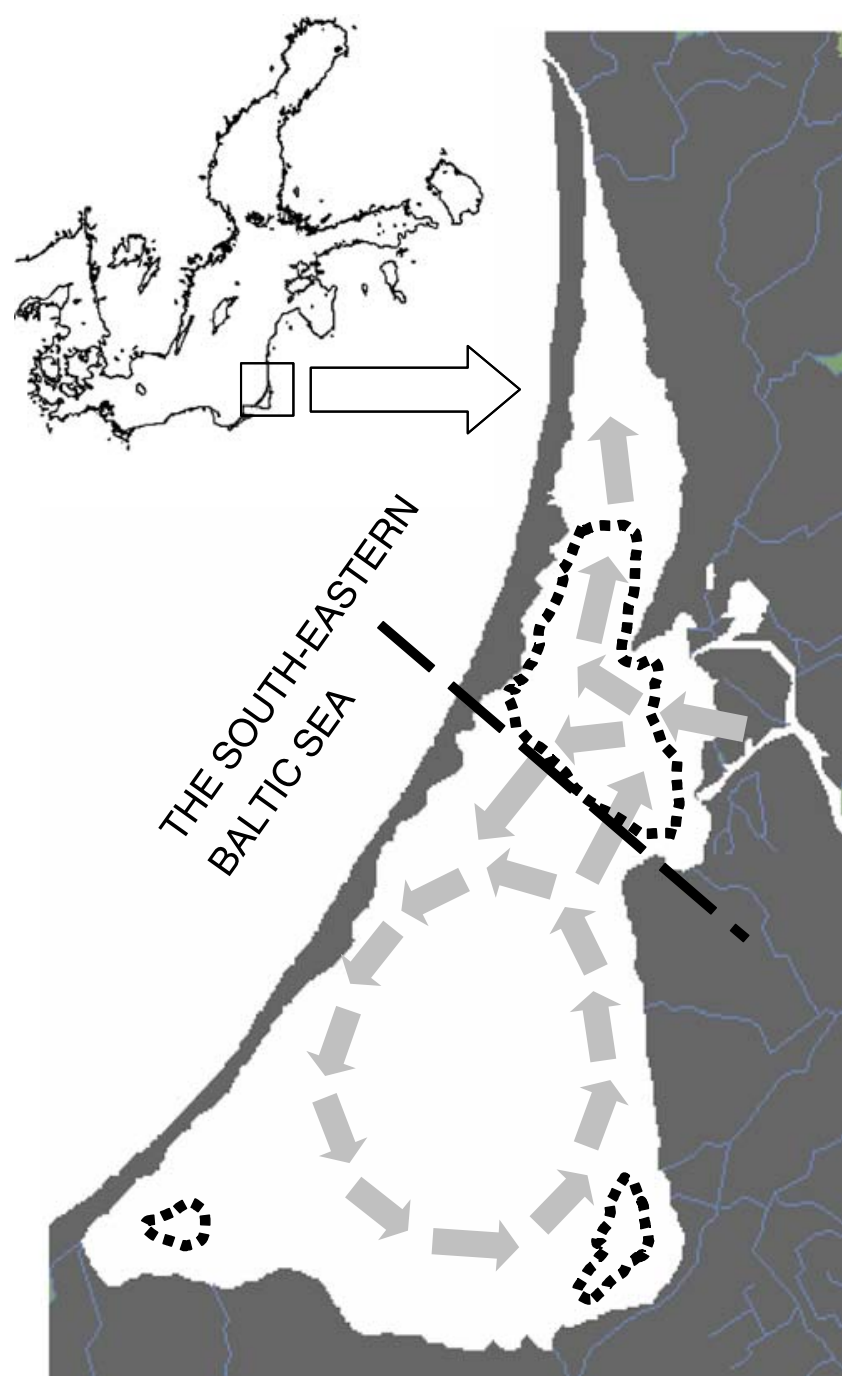

Fig. 1 Area colonised by D. polymorpha in the Curonian lagoon (doted line) with principal scheme of dominant currents (arrows). Dashed line indicates boundary used to quantify water exchange between southern part and zebra mussels bed by $2 \mathrm{D}$ hydrodynamic model SHYFEM times and carries annually about 437,000 tons of particulate material (Galkus 1995; Galkus and Joksas 1997) (Fig. 2). Production of organic particulate material in the lagoon is higher than TPM input from the freshwater source. This was estimated to be about 610,000 tons. Approximately $40 \%$ of the received and produced TPM is carried into the sea, while the rest is retained within the lagoon annually (Fig. 2).

\section{Methods}

Quantitative characteristics of the D. polymorpha population were obtained from a long-term (1980-2002) monitoring dataset (4 permanent stations, 270 samples) and the results of several surveys carried out during the period 1999-2004 (20 stations, 120 samples in total). Samples were collected and treated following standard guidelines for bottom macrofauna sampling (HELCOM 1988).

The impact of the zebra mussel population on TPM in the Curonian lagoon was estimated using a TPM budget for the zebra mussels' bed. Assuming conditions of steady state and full mixing of the water column, the following balance equation was used to describe the TPM budget:

$\mathrm{Pr}+\mathrm{In}_{\mathrm{R}}+\mathrm{In}_{\mathrm{S}}-$ Dep + Res - Out $=0$,

where $\operatorname{Pr}=$ amount of TPM produced above the zebra mussels bed; $\mathrm{In}_{\mathrm{R}}=$ amount of TPM supplied by the river Nemunas; $\mathrm{In}_{\mathrm{S}}=$ amount of TPM transported to the bed with inflowing waters from the southern part; Dep = amount of TPM deposited in the bed; Res $=$ amount of resuspended TPM; Out $=$ amount of TPM transported from the bed.

Two sources of the incoming TPM were taken into account: (1) Nemunas River runoff passing the bed $\left(\operatorname{In}_{\mathrm{R}}\right)$, and (2) the return flux from the southern part of the Curonian lagoon adjacent to the bed $\left(\operatorname{In}_{\mathrm{S}}\right.$.). The freshwater TPM input was calculated using literature data on water fluxes from the Nemunas River and suspended material concentrations in the incoming water (Galkus 1995; Galkus and Joksas 1997) (Table 1). The

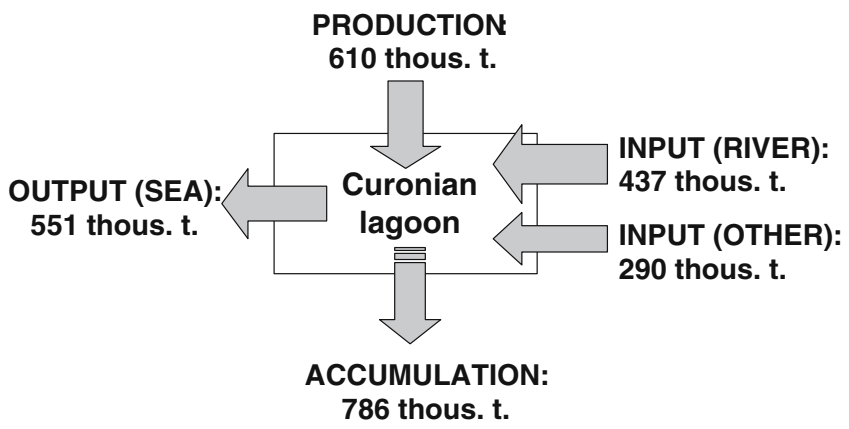

Fig. 2 Annual TPM budget for the Curonian lagoon. Values taken from Galkus and Joksas (1997) 
Table 1 System characteristics used as input data in the budget formula

\begin{tabular}{|c|c|c|c|c|}
\hline Parameter/season & Spring & Summer & Autumn & Winter \\
\hline${ }^{\mathrm{a} S p e c i f i c}$ TPM production, day $^{-1}$ (a) & 0.010 & 0.017 & 0.014 & 0.007 \\
\hline${ }^{\mathrm{a} T P M}$ conc. in Nemunas water, $\mathrm{g} \mathrm{m}^{-3}$ & 20.5 & 34.0 & 14.0 & 10.5 \\
\hline TPM conc. in the southern part, $\mathrm{g} \mathrm{m}^{-3}$ & 13.0 & 30.9 & 39.1 & 6.0 \\
\hline 'a TPM conc. in Dreissena bed, $\mathrm{g} \mathrm{m}^{-3}$ & 17.6 & 31.2 & 26.0 & 4.5 \\
\hline${ }^{\mathrm{b}}$ Water flux from the southern part, $\left(\times 10^{6}\right) \mathrm{m}^{3} \mathrm{day}^{-1}$ & 49.5 & 33.3 & 53.0 & 60.1 \\
\hline${ }^{a}$ Water flux from Nemunas, $\left(\times 10^{6}\right) \mathrm{m}^{3}$ day $^{-1}(Q)$ & 105.5 & 40.0 & 51.1 & 58.9 \\
\hline
\end{tabular}

abudget elements recalculated from Galkus (1997) and Galkus and Joksas (1997)

budget elements estimated using 2D hydrodynamic SHYFEM model (Umgiesser et al. 2004)

same publications were used to obtain data on TPM concentrations in the southern part of the lagoon, while water exchange was quantified using $2 \mathrm{D}$ finite element hydrodynamic model SHYFEM (Umgiesser et al. 2004).

Local TPM production for the budget calculations was taken from Galkus and Joksas (1997) assuming a homogenous distribution in the central part of the lagoon. Since the central part was reported as a transitional environment with no physical deposition of suspended material (Galkus and Joksas 1997; Pustelnikovas 1998), the uptake of the particulate material by $D$. polymorpha was assumed to be the main process responsible for TPM downward flux (see also Discussion):

$\mathrm{UR}=\mathrm{CR}(h) \cdot \mathrm{TPM}$,

where UR $=$ uptake rate in $\mathrm{g} \mathrm{m}^{-3}$ day $^{-1}, \mathrm{CR}(h)=$ volume specific clearance rate (i.e. area specific clearance rate divided by depth) of zebra mussels in $\mathrm{m}^{3} \mathrm{~m}^{-3}$ day ${ }^{-1}$; TPM = concentration of TPM in the water column above the bed in $\mathrm{g} \mathrm{m}^{-3}$.

Following assumptions above, the amount of resuspended TPM was described as biodeposits, which are returned to the water column:

$\operatorname{Res}=h \cdot(F c+P s F c)$,

where $h=$ fraction of resuspended biodeposits; $F c=$ amount of faeces in the zebra mussel bed; $P S F c=$ amount of pseudofaeces in the zebra mussel bed. Rates of faeces and pseudofaeces production were quantified following equations:

$F c R=(1-F P O M \cdot g) \cdot(1-f) \cdot \mathrm{CR}(h) \cdot \mathrm{TPM}$,

$P_{S} F_{C} R=f \cdot \mathrm{CR}(h) \cdot \mathrm{TPM}$,

where $F c R=$ faeces production rate in $\mathrm{g} \mathrm{m}^{-3} \mathrm{day}^{-1}$; $P S F c R=$ pseudofaeces production rate in $\mathrm{g} \mathrm{m}^{-3}$ day $^{-1}$; FPOM = fraction of organic material in TPM; $f=$ fraction of pseudofaeces in rejected material (Klepper 1989; Herrman 1993); $g=$ assimilation coefficient of organic material (derived from Schneider et al. 1998).

Taking into account the above conditions, the balance equation (1) was transformed into the following equation describing dynamics of TPM in the $D$. polymorpha bed for each season:

$$
\begin{aligned}
& \{a-\mathrm{CR}(h)+h \cdot[f \cdot \mathrm{CR}(h)+(1-f) . \\
& (1-\mathrm{FPOM} \cdot g) \cdot \mathrm{CR}(h)]\} \cdot \mathrm{TPM}-\frac{Q}{V} \cdot \mathrm{TPM} . \\
& (1+p)+\frac{Q}{V} \cdot \mathrm{TPM}_{\mathrm{R}}+\frac{p \cdot Q}{V} \mathrm{TPM}_{\mathrm{S}}=0,
\end{aligned}
$$

where $a=$ TPM net production (Galkus and Joksas 1997) in $\mathrm{g} \mathrm{m}^{-3} \mathrm{day}^{-1} ; h=$ fraction of resuspended biodeposits; $V=$ water volume above the bed in $\mathrm{m}^{3}$; $Q=$ water flux from the Nemunas River in $\mathrm{m}^{3}$ day $^{-1}$; $p=$ ratio of the incoming water flux from the southern part and the Nemunas River; $\mathrm{TPM}_{\mathrm{R}}=\mathrm{TPM}$ concentration in the Nemunas runoff in $\mathrm{g} \mathrm{m}^{-3}$; $\mathrm{TPM}_{\mathrm{S}}=\mathrm{TPM}$ concentration in the southern part of the Curonian lagoon.

Since the extent of biodeposit resuspension was unknown, lower and upper limits for the zebra mussels' clearance rate were estimated using two scenarios: (1) no resuspension of biodeposits occurs $(h=0)$; and (2) all biodeposits are resuspended $(h=1)$. The following equation was derived from (2) for volume specific clearance rate:

$$
\mathrm{CR}(h)=\frac{\mathrm{TPM}_{\mathrm{R}}+p \cdot \mathrm{TPM}_{\mathrm{S}}-\mathrm{TPM} \cdot\left(1-a \cdot \frac{V}{Q}+p\right)}{[1-h \cdot(1-\mathrm{FPOM} \cdot g \cdot(1-f))] \cdot \mathrm{TPM} \cdot \frac{V}{Q}}
$$

Two parameters were used to characterise impact of zebra mussels on TPM in the water column. Clearance time, based on the volume specific clearance rate, was used to quantify the time needed to filter all particulated material entering the bed. This measure along with the water residence time (period of time needed to replace the water mass above the bed) was used in several studies (Heip et al. 1995; Dame 1996) to compare rates of particle transport driven by hydrodynamic and biological (suspension feeding) factors. Along with this approach, the net deposition defined as a difference between the amount of material filtered from the water column (uptake) and the amount of resuspended biodeposits were used as an alternative measure of suspension feeding impact on TPM. An equation for net deposition was derived from eqs. 2 and 3, and in contrast to the volume 
specific clearance rate (3) this was independent of the extent of resuspension:

$$
\begin{aligned}
\operatorname{Dep}_{\mathrm{NET}} & =\text { Dep }- \text { Res }=\frac{Q}{V} . \\
& {\left[\mathrm{TPM}_{\mathrm{R}}+p \cdot \mathrm{TPM}_{\mathrm{S}}-\mathrm{TPM} \cdot\left(1-a \cdot \frac{V}{Q}+p\right)\right], }
\end{aligned}
$$

where Dep $_{\mathrm{NET}}=$ net deposition in $\mathrm{g} \mathrm{m}^{-3} \mathrm{day}^{-1}$; $a=$ TPM production above the bed in $\mathrm{g} \mathrm{m}^{-3} \mathrm{day}^{-1}$.

In order to test the reliability of clearance rate estimates obtained from the TPM budget approach, 0dimensional clearance model for zebra mussel populations (Zemlys et al. 2001) was used assuming steady state for the seasons. The model estimates clearance rate of the population using its average biomass, water temperature and TPM concentration in the water column (Table 2). Since the net clearance rate of mussels in clumps is lower than that of separate individuals due to refiltration (Yu and Culver 1999), a basal clearance rate and a refiltration factor were introduced into the model (Table 2). A filtering activity of $16 \mathrm{~h} \mathrm{day}^{-1}$ was assumed following the results from various studies (Morton 1969; Walz 1978; Horgan and Mills 1997).

\section{Results}

The population of $D$. polymorpha forms dense non-attached clumps of individuals on soft bottoms of the Curonian lagoon. Such beds of zebra mussels are directly exposed to the Nemunas River outflow (Fig. 1) and occupy about $300 \mathrm{~km}^{2}$ or approximately $20 \%$ of the lagoon's bottom. Shell free dry weight (SFDW) and density of the zebra mussels in the area ranges from 0.5 to $0.5 \times 10^{4} \mathrm{~g} \mathrm{~m}^{-2}$ and from 40 to $57 \times 10^{3}$ ind $\mathrm{m}^{-2}$, respectively, with the $14-20 \mathrm{~mm}$ size class dominant in the population. Due to negatively skewed distributions, a median density of $12.6 \times 10^{3} \pm 2.8 \times 10^{3}$ ind $\mathrm{m}^{-2}$ and median biomass $15.7 \pm 0.8 \mathrm{~g}$ SFDW $\mathrm{m}^{-2}$ were used in the calculations below.

Approximately 806,000 tons of TPM enters the $D$. polymorpha bed annually: ca. $54 \%$ comes from the Nemunas River and ca. $46 \%$ from the southern part of the lagoon adjacent to the bed. Amount of TPM brought into the bed with the freshwater runoff is the highest in spring and gradually decreases towards winter (Fig. 3). Decline in freshwater TPM input during summer and autumn is compensated by the TPM flux from the southern part, which reaches the highest level in autumn. Therefore, the TPM supply into the mussel bed is relatively constant, except during winter when it is $2-3$ times lower. The local TPM production over the bed $(112,000$ tons) makes approximately $12 \%$ of the total annual input.

Annually the population of zebra mussels is depositing approximately one quarter of the TPM passing the bed. The lowest figure was found for spring $(10 \%)$, while in summer and autumn the relative amount of deposited TPM increases (up to $18-30 \%$ ). Approximately $87 \%$ of the total removed material is deposited in a form of faeces and pseudofaeces and $13 \%$ is assimilated into the body weight of mussels. Outflow of TPM from the bed is relatively constant (206,000-246,000 tons) except during winter (Fig. 3).

The seasonal clearance rate estimated using the population clearance model ranged between 1.1 and $11.8 \mathrm{I} \mathrm{g}^{-1}$ SFDW day ${ }^{-1}$ during the year (average $7.4 \pm 2.31 \mathrm{~g}^{-1}$ SFDW $\mathrm{day}^{-1}$ ) (Fig. 4). These values generally fitted well into the ranges of the seasonal clearance rates estimated from the TPM budget using two resuspension scenarios (no resuspension or all biodeposits resuspended). However, the modelled rate for the winter period was considerably lower. Excluding this period, the modelled clearance rates were on average 2.5 times higher than the values estimated from the budget

\begin{tabular}{|c|c|c|}
\hline Variable or parameter & Explanation & Comments/literature \\
\hline $\mathrm{CR}=a_{\mathrm{CR}} \cdot \mathrm{RC}(D) \cdot \mathrm{CR}_{0} \cdot f_{\mathrm{TPM}}(\mathrm{TPM}) \cdot f_{T}(T)$ & $\begin{array}{l}\text { Clearance rate, } \\
\mathrm{m}^{3} \mathrm{day}^{-1}\end{array}$ & \\
\hline $\begin{array}{l}\mathrm{CR}_{0}=a_{\mathrm{CR}} \cdot D \\
a_{\mathrm{CR}}=0.16 \pm 0.002\end{array}$ & $\begin{array}{l}\text { Basal clearance rate, } \\
\mathrm{m}^{3} \text { day }^{-1}\end{array}$ & $\begin{array}{l}\text { Based on individual clearance rate } \\
\text { by Kryger and Riisgard (1988) and } \\
\text { median biomass of Dreissena } \\
\text { in the Curonian lagoon }\end{array}$ \\
\hline $\begin{aligned} \mathrm{RC}(D) & =a_{\mathrm{RC}} \cdot \exp \left(-b_{\mathrm{RC}} \cdot D\right), \mathrm{R}^{2}=0.86 \\
a_{\mathrm{RC}} & =0.258 \pm 0.019 \\
b_{\mathrm{RC}} & =0.0069 \pm 0.00096\end{aligned}$ & Refiltration factor & $\begin{array}{l}\text { Based on results from Yu and } \\
\text { Culver (1999) and } \\
\text { our laboratory experiments }\end{array}$ \\
\hline $\begin{array}{l}f_{T}(T)= \begin{cases}\exp \left(a_{T} \cdot(T-10)\right), & T \leq 10^{\circ} \mathrm{C} \\
1, & T>10^{\circ} \mathrm{C},\end{cases} \\
a_{T}=0.35\end{array}$ & Temperature factor & Sprung (1995) \\
\hline $\begin{array}{l}f_{\mathrm{TPM}}(\mathrm{TPM})=\exp \left(-a_{\mathrm{TPM}} \cdot \mathrm{TPM}\right) \\
a_{\mathrm{TPM}}=0.037 \\
\mathrm{D} \\
\mathrm{T}\end{array}$ & $\begin{array}{l}\text { Suspended material factor } \\
\text { Biomass, g SFDW } \mathrm{m}^{-2} \\
\text { Water temperature, }{ }^{\circ} \mathrm{C}\end{array}$ & $\begin{array}{l}\text { Reeders et al. (1989), Reeders and } \\
\text { Bij de Vaate, (1990, 1992), } \\
\text { Long-term average (see text for explanations) } \\
\text { Long-term average (Jurevicius 1959; Dubra 1995) }\end{array}$ \\
\hline
\end{tabular}

Table 2 Description of main variables and parameters of 0-D population clearance rate model 
Fig. 3 Seasonal TPM budgets for the zebra mussels bed $(\Leftarrow$ input from the Nemunas River; $\Rightarrow$ input from the southern part; $\Uparrow$ output from the bed; $\Downarrow$ deposition; 「 local TPM production)
SPRING

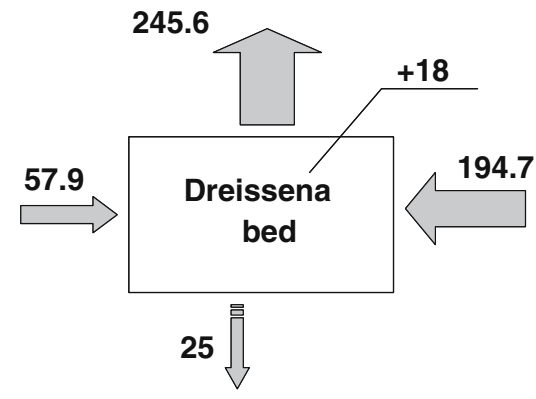

AUTUMN

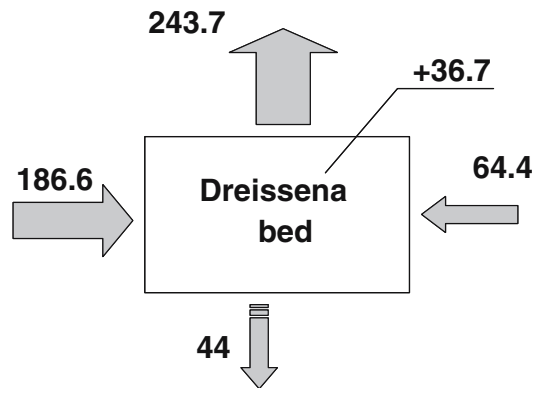

SUMMER

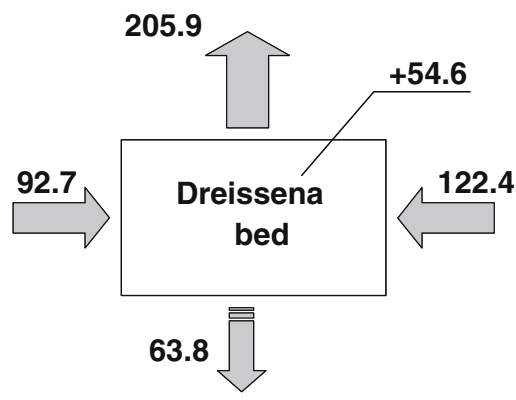

WINTER

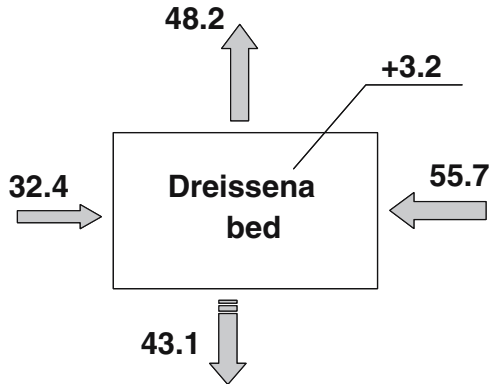

assuming the no resuspension scenario. In case all biodeposited material is resuspended, the modelled and the budget estimates of the clearance rates followed different seasonal patterns.

The estimated clearance time indicates that 47 days on an average are needed for zebra mussels to remove all TPM present in the water column above the bed (if no resuspension occurs), while the residence time in the area occupied by zebra mussels is 11 days (Fig. 5). In spring, during the period of the maximum TPM load, the highest difference between clearance and residence time (70 and 7 days, respectively) is found. In summer and autumn months, when the water flow is reduced and the clearance rate of mussels is relatively high, the difference between residence and clearance time decreases. At low
TPM concentrations during winter, increased clearance rates result in relatively short clearance time, which is comparable with residence time (10 and 9 days respectively). This ratio is opposite if full resuspension of biodeposits is assumed (Fig. 5). In this case, the clearance time is $2-5$ times shorter than water residence time (11 days in average) and relatively constant between seasons ( 3 days in average).

\section{Discussion}

Estimates of filtered water volumes and subsequent ecosystem effects vary significantly depending on the population characteristics of the suspension feeder as
Fig. 4 Comparison of seasonal clearance rates obtained from the population clearance model and TPM budget calculations using two resuspension scenarios

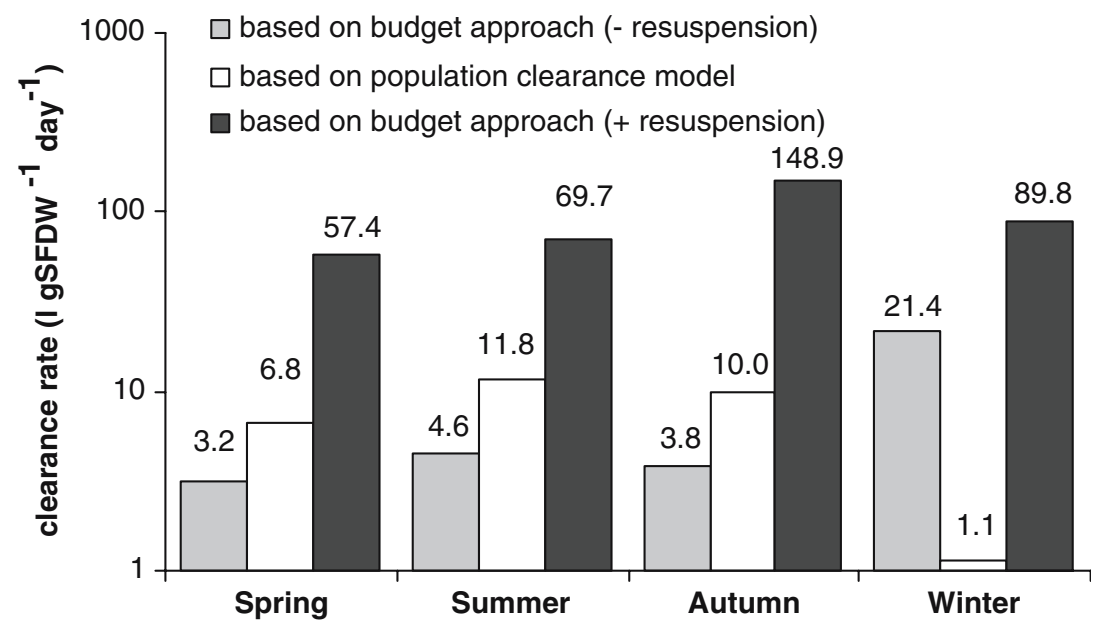


Fig. 5 Water residence time in the zebra mussel bed and TPM clearance time estimated from TPM budget calculations using two resuspension scenarios

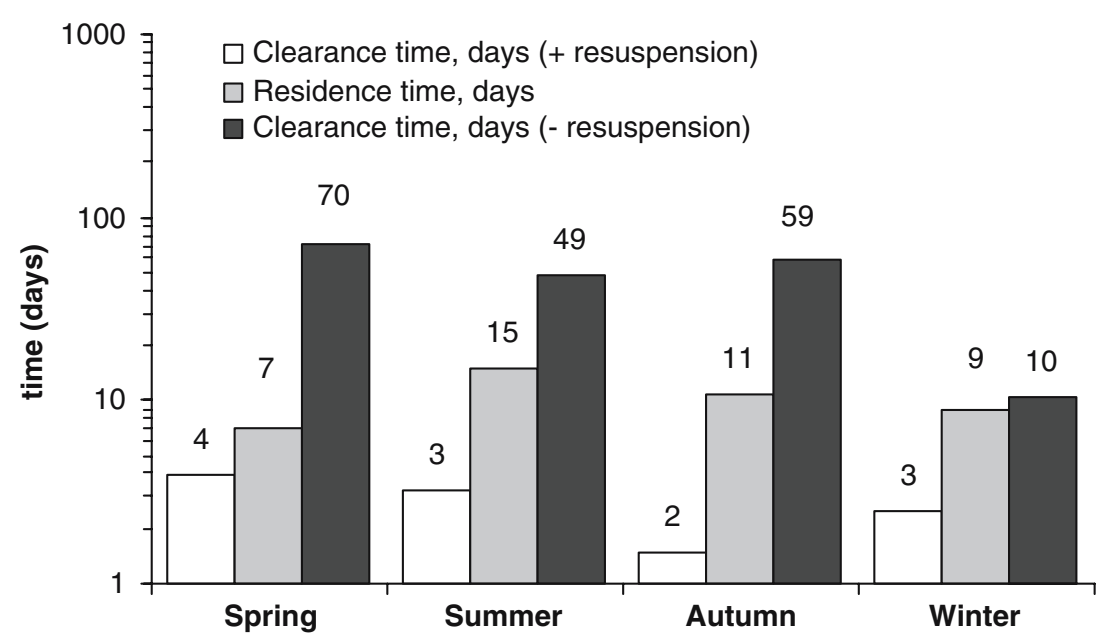

well as intrinsic hydrographic conditions (depth, residence time) of the water body (Dame 1996). Time needed for D. polymorpha to filter the whole water volume also ranges from several hours (e.g. Fanslow et al. 1995; MacIsaac et al. 1992) to weeks or months (Stanczykowska 1977; Reeders et al. 1989).

In this study the impact of $D$. polymorpha on TPM flow in the enclosed shallow lagoon was estimated from the seasonal TPM budgets for the water column above the mussel bed taking into account the water residence time. Physical sedimentation was reported to be unimportant in this part of the lagoon (Galkus and Joksas 1997; Pustelnikovas 1998), while zooplankton grazing in summer was estimated in a range between 5 and $10 \%$ of TPM (Gasiunaite and Razinkovas 2000). We also assumed a negligible effect of other large suspension feeders (mainly Unio tumidus, but also $U$. pictorum, Anodonta cygnea and A. piscinalis) on TPM deposition due to their low occurrence $(<30 \%)$ and very low densities (in most of the samples only single individuals were found). Therefore, our calculated estimates of the $D$. polymorpha impact should be considered as maximal.

The upper and lower limits of the clearance rate of zebra mussels were estimated from the TPM budget considering two resuspension scenarios. Generally, the seasonal variations in the clearance rate followed a temperature dynamics in the lagoon and the TPM supply into the mussel bed. There was general agreement between the modelled and the budget based estimations for all seasons except winter. Very high clearance rate calculated from the budget for this season reflected exceptionally high retention of the allochtonous TPM, approximately $45 \%$ of the input retained within the zebra mussel bed in contrast to less than $4 \%$ in other seasons. A possible reason for overestimation of the winter clearance rate may be an increased physical sedimentation in the lagoon under ice cover. Also, in our model the reduction of clearance rates at temperatures below $10^{\circ} \mathrm{C}$ was assumed (based on Sprung 1995), while other authors (e.g. Smaal et al. 1997) excluded the temperature factor in the modelling of suspension feeding. It is obvious that our limited knowledge on the temperature effect on clearance rate requires more experiments. Additionally, the deviation of the results from two approaches might be caused by the TPM input data. Compared to other seasons a low number of winter samples was available (Galkus and Joksas 1997) and the budget based clearance rate was highly dependent on TPM concentrations: e.g. a decrease in TPM concentration by $15 \%$, from 31 to $26 \mathrm{~g} \mathrm{~m}^{-3}$, would result in an almost two times decrease in clearance rate.

Both approaches gave relatively consistent values (the budget based: 2-64 ml ind ${ }^{-1} \mathrm{~h}^{-1}$ (no resuspension of biodeposits) and 171-440 (all biodeposits resuspended); the modelled: 4-32 $\mathrm{ml}^{\text {ind }}{ }^{-1} \mathrm{~h}^{-1}$ ) in a context of highly variable clearance rates obtained for $D$. polymorpha in various studies (between 1 and $500 \mathrm{ml}$ ind $^{-1} \mathrm{~h}^{-1}$ : for reviews see Kryger and Riisgård 1988; Bunt et al. 1993; Ackerman 1999; Yu and Culver 1999). Perhaps due to the much longer time scales (seasons) than most literature estimates (usually hours to days), the clearance rates obtained in our study are mainly in the lower range of published values. Our estimates (excluding for scenario of biodeposit resuspension) are also lower than potential clearance rates (approximately $100 \mathrm{ml}$ ind $^{-1} \mathrm{~h}^{-1}$ ) (Kryger and Riisgård 1988) for individuals of the same average shell length. Many laboratory experiments do not take into account effects leading to reduction of the clearance rate in natural conditions (e.g. high near bottom flows or high levels of inorganic TPM fraction).

Another reason for relatively low clearance rates in our study could be the overestimated average biomass of zebra mussels, since their clumps are patchy in distribution and vary in size. However, using an empirical relationship (Heip et al. 1995) between volume specific biomass of mussels and average lagoon's water residence time of 18 days for the lagoon, we obtained an area specific biomass of $15.5 \mathrm{~g}$ SFDW $\mathrm{m}^{-2}$. This value is highly consistent with the actual median biomass of 
15.7 $\mathrm{g}$ SFDW $\mathrm{m}^{-2}$ estimated for the zebra mussels in the Curonian lagoon.

Clearance to residence time ratio $(=1)$ was used to differentiate systems controlled by suspension feeders (ratio <1) from those dominated by hydrodynamic forcing (ratio > 1) (Dame 1996). This ratio in our study was highly dependent on the fate of biodeposits. The values obtained were higher than one if all biodeposits were resuspended, and lower than one if biodeposits were retained in the bed. Due to resuspension of biodeposits and their potential refiltration, the clearance time based on the clearance rate, only partly reflects the impact of zebra mussels on TPM, since the low clearance time in conditions of high resuspension rates would not necessarily result in decreased TPM concentrations in the water column. Therefore, interpretation of the clearance to residence time ratio in shallow systems with predominant resuspension might be difficult.

An alternative measure of zebra mussel impact on TPM transport may be based on the ratio between TPM input and the amount of TPM, which is biodeposited in the bed. The constructed seasonal TPM budgets show the ability of zebra mussels to deposit between 10 and $30 \%$ of TPM entering the bed (excluding local production when the winter period is neglected). The relative amount of biodeposited TPM agrees well with residence time, being the lowest in spring $(10 \%$, residence time 7 days $)$ and highest in summer $(30 \%$, residence time 15 days). This demonstrates predominance of lateral TPM transport rather than a significant contribution of suspension feeding in the deposition processes. Short water residence time within the mussel bed impedes efficient removal of large TPM amounts and could be considered as a main factor diminishing the role of suspension feeding in TPM transport in the lagoon.

A large part of the TPM is transported to the sea, but it also enters the relatively isolated southern part of the lagoon where it is deposited and mineralised. This sedimentation area $\left(\sim 1,020 \mathrm{~km}^{2}\right.$, Galkus and Joksas 1997) is approximately 3.5 times larger than the zebra mussel bed in the lagoon and acts as an important source of nutrients, accelerating high local primary production. However, annual TPM uptake by suspension feeding zebra mussels (176,000 tons) is approximately half the amount of TPM deposited in the southern part of the lagoon $(388,000$ tons, Galkus and Joksas 1997), while annual biosedimentation rate $\left(\sim 590 \mathrm{~g} \mathrm{~m}^{-2}\right)$ in the D. polymorpha bed is even higher than physical deposition rate $\left(\sim 380 \mathrm{~g} \mathrm{~m}^{-2}\right)$ in the sedimentation areas. The principal difference lies in the fate of biodeposited and sedimented particles, since biodeposits are transferred to the bottom under relatively high-energy conditions at depths of $\sim 3.5 \mathrm{~m}$, while physical sedimentation occurs in accumulation bottoms at 5-6 $\mathrm{m}$ depth. Even though little is known about the residence time of biodeposited particles, part of this material serves a food source for various benthic species, which are found in significantly higher numbers within the clumps of mussels than in adjacent sediment (Daunys 2001). Therefore, instead of changing TPM transport pathways at the ecosystem scale, biodeposition may appear to be of high importance in increasing efficiency of organic material transfer between trophic groups as well as in maintenance of biodiversity at the local scales.

\section{Conclusions}

Dreissena polymorpha became an additional agent of TPM sink in the lagoon after its invasion. However, the species is not capable to control TPM transport. This is primarily determined by natural ecosystem constraints such as the hydrologic regime and hydrographic conditions. On the other hand, along with the zebra mussel invasion the biological transfer of particulate material from the water column to the bottom was also made possible in areas originally devoid of physical sedimentation. Estimated biodeposition rate per surface unit in the mussel bed is higher than the physical deposition rate in the sedimentation areas. Even though the fate of biodeposited particles remains poorly known, local effects of suspension feeding associated with significantly increased organic material availability for other trophic groups of benthic fauna may appear to be more significant than effects on TPM pathways at the ecosystem scale.

Acknowledgements This study was supported by the EU FW6 Integrated Project 506675 ALARM "Assessing Large-scale environmental risks with tested methods", EU FW6 Contract Nr. 505406 MARBEF "Marine Biodiversity and Ecosystem Functioning" and the Lithuanian State Science and Studies Foundation grants Nr. 21125 and Nr. T-05144. This publication is contribution number MPS-06006 of MarBEF.

\section{References}

Ackerman JD (1999) Effect of velocity on the filter feeding of dreissenid mussels (Dreissena polymorpha and Dreissena bugensis): implications for trophic dynamics. Can J Fish Aquat Sci 56:1551-1561

Bunt CM, MacIsaac HJ, Sprules WG (1993) Pumping rates and projected filtering impacts of juvenile zebra mussels (Dreissena polymorpha) in western Lake Erie. Can J Fish Aquat Sci 56:1017-1022

Dame RF (1996) Ecology of marine bivalves. An ecosystem approach. CRC Press, Boca Raton

Daunys D (2001) Patterns of the bottom macrofauna variability and its role in the shallow coastal lagoon. Summary of PhD Thesis, Klaipeda University

Dubra J (1995) Oceanographic conditions. Annual report of marine research center. Ministry of environment, marine research center, Klaipèda 19-32

Galkus A (1995) The budget of thin dispersed sedimentary matter in the Curonian lagoon. In: Gudelis V, Povilanskas R, Roepstorff A (eds) Coastal conservation and management in the Baltic Region. Proceedings of the EUCC-WWF Conference, 28 May, 1994, Klaipeda, pp 29-32

Galkus A, Joksas K (1997) Sedimentary material in the transitional aquasystem. Institute of Geography, Vilnius, pp 42-104 
Gasiunaite ZR, Razinkovas A (2000) The role of plankton and nektobenthos crustaceans in the primary production transformation in the Curonian lagoon (in Lithuanian with English summary). Ekologija 3:22-27

Gasiunas I (1959) Macrozoobenthos of the Kursiu Marios. In: Jankevicius K, Gasiunas I, Gediminas A, Gudelis V, Kublickas A, Maniukas I (eds) Kursiu Marios, Lithuanian Academy of Sciences, Vilnius, pp 191-292

Heip CHR, Goosen NK, Herman PMJ, Kromkamp J, Middelburg JJ, Soetaert K (1995) Production and consumption of biological particles in temperate tidal estuaries. Oceanogr Mar Biol Ann Rev 33:1-149

Herman PMJ (1993) A set of models to investigate the role of benthic suspension feeders in estuarine ecosystems. In: Dame RF (eds) Bivalve filter feeders in estuarine and coastal ecosystem processes. Springer Verlag, Berlin, pp 421-454

HELCOM (1988) Guidelines for the Baltic monitoring programme for the third stage. Part D. Biol Determ 27D:23-87

Horgan MJ, Mills EL (1997) Clearance rates and filtering activity of zebra mussel (Dreissena polymorpha): implications for freshwater lakes. Can J Fish Aquat Sci 54:249-255

Jurevicius R (1959) Hydrodynamic conditions in the Curonian Lagoon. In: Jankevicius K, Gasiunas I, Gediminas A, Gudelis V, Kublickas A, Maniukas I (eds) Kursiu Marios, Lithuanian Academy of Sciences, Vilnius, pp 69-108

Karatayev AY, Burlakova LE, Padilla DK (2002) Impacts of zebra mussels on aquatic communities and their role as ecosystem engineers. In: Leppäkoski E, Gollasch S, Olenin S (eds) Invasive aquatic species of Europe-distribution, impact and management. Kluwer Academic Publishers, Dordrecht, pp 433-446

Klepper O (1989) A model of carbon flows in relation to macrobenthic food supply in the Oosterschelde estuary. Ph D thesis, University of Wageningen, 270pp

Kryger J, Riisgård HU (1988) Filtration rate capacities in 6 species of European freshwater bivalves. Oecologia 77:34-38

Morton B (1969) Studies on the biology of Dreissena polymorpha Pall II. Correlation of the rhythms of adductor activity, feeding, digestion and excretion. Proc Malac Soc Lond 38:401-414

Olenin S, Leppäkoski E (1999) Non-native animals in the Baltic Sea: alteration of benthic habitats in coastal inlets and lagoons. Hydrobiologia 393:233-243
Olenin S, Orlova M, Minchin D (1999) Dreissena polymorpha (Pallas, 1771). In: Gollasch S, Minchin D, Rosenthal H, Voigt $M$ (eds) Case histories on introduced species: their general biology, distribution, range expansion and impact. Logos-Verlag, Berlin, pp 37-42

Pustelnikovas O (1998) Geochemistry of sediments of the Curonian Lagoon. Institute of Geography, Lithuania

Reeders HH, Bij de Vaate A (1990) Zebra mussels (Dreissena polymorpha): a new perspective for water quality management. Hydrobiologia 200/201:437-450

Reeders HH, Bij de Vaate A (1992) Bioprocessing of polluted suspended matter from the water column by the zebra mussel (Dreissena polymorpha Pallas). Hydrobiologia 239:53-63

Reeders HH, Bij de Vaate A, Slim FJ (1989) The filtration rate of Dreisssena polymorpha (Bivalvia) in three Dutch lakes with reference to biological water quality management. Freshw Biol 22:133-141

Schneider DW, Madon SP, Stoeckel JA, Sparks RE (1998) Seston quality controls zebra mussel (Dreissena polymorpha) energetics in turbid rivers. Oecologia 117:331-341

Smaal AC, Vonck APAM, BakkerA (1997) Seasonal variation in physiological energetics of Mytilus edulis and Cerastoderma edule of different size classes. J Mar Biol Ass UK 77:817-838

Sprung M (1995) Physiological energetics of the zebra mussel Dreissena polymorpha in lakes II. Food uptake and gross growth efficiency. Hydrobiologia 304:133-146

Stanczykowska A (1977) Ecology of Dreissena polymorpha (Pall.) (Bivalvia) in lakes. Pol Arch Hydrobiol 24:461-530

Umgiesser G, Melaku Canu D, Cucco A, Solidoro C (2004) A finite element model for the Venice Lagoon. Development, set up, calibration and validation. J Mar Syst 51:23-145

Walz N (1978) The energy balance of the fresh mussel Dreissena polymorpha Pallas in laboratory experiments and in lake Constance. I. Pattern of activity, feeding and assimilation efficiency. Arch Hydrobiol 55(1):83-105

Yu N, Culver DA (1999) Estimating the effective clearance rate and refiltration by zebra mussels, Dreissena polymorpha, in stratified reservoir. Freshw Biol 41:481-492

Zemlys P, Daunys D, Olenin S (2001) Modeling of zebra mussel impact on ecosystem of the Curonian lagoon (in Lithuanian). Scientific Report to Lithuania Science Foundation 